\title{
International Students' Reflections on Employability Development Opportunities During a One-Year Masters-level Program in the UK
}

\author{
Omolabake Fakunle \\ University of Edinburgh, Scotland \\ Anne Pirrie \\ University of the West of Scotland
}

\begin{abstract}
This article explores reflection and reflective thinking, drawing upon qualitative research on international students' perceptions of developing their employability while studying in the UK. It addresses a gap in the literature by making a connection between internationalization and employability, concepts that are mainly framed as separate discursive realms. The literature on internationalization is focused around international student recruitment and the benefits to the host institution; the employability discourse is oriented towards national policies on the development of human capital through home students in the domestic market. The reflective thinking demonstrated by the international students illustrates the challenges they faced in seeking opportunities to enhance their employability within and outside the university; and to (re)assess learning opportunities that are integrated with work experience. The findings suggest that there is scope for embedding employment development opportunities (EDOs) at a systemic level in order to enhance the experience of international students.
\end{abstract}

Keywords: internationalization, employability, international students, workintegrated learning, employment development opportunities

The internationalization agenda has given rise to the presence of large numbers of international students on university campuses across the UK. Despite the availability of data on student numbers collected by national agencies, (e.g. the Higher 
Educational Statistics Agency (HESA) in the UK and supranational organisations such as the OECD), there are concerns about the lack of insight into international students' employability (Huang et al., 2014). In the UK context, this gap can be linked to a lack of alignment of internationalization and employability discourses. The literature on internationalization is framed around international student recruitment and the associated benefits to the host institutions/countries (Lomer, 2018). In contrast, the employability discourse is oriented towards developing the skills and knowledge of home students (Tomlinson, 2008; Tymon, 2013) as part of a human capital driven national policy (Yorke, 2004). As Gillies (2015, p.1) notes, the human capital perspective "[promotes] education as an "investment" which yields returns in due course to the individual in terms of pay and to the state in terms of employment and economic growth". The theory is encapsulated and expressed in the definition of employability as developing knowledge, skills and attitudes to improve the likelihood of obtaining and retaining fulfilling work (Hillage \& Pollard, 1998). This underpins the focus on employability in quantitative and qualitative terms and the role of higher education to produce employable graduates. The employability narrative in the UK is operationalized by the HESA. Prior to 2017, HESA used the Destinations of Leavers from Higher Education survey that captured the numbers of graduates in employment six months after finishing their studies in UK universities, as a measure of employability. These data excluded international students. The new HESA Graduate Outcomes survey was initiated in 2017/18 and the first report released in June 2020 did not include specific employability-related data on non-European international students. It remains unclear how future employability-related policy will take account of the impact of the Covid-19 pandemic.

However, universities around the world, including in the UK, aim to recruit students from a global pool and to 'produce' graduates who are prepared to live and work in a global world, under the banner of an internationalization agenda. Research has shown that the prospect of enhanced employability is a key driver for international students studying abroad (Archer, 2016; Fakunle, 2020; Nilsson \& Ripmeester, 2016). This article brings these discrete policy discourses into alignment and explores the tensions between them by focusing on the reflections of international students (Fakunle, 2019a). As Fakunle (2019b) and Page and Chahboun (2019) have pointed out, the voices of international students are largely absent from the relevant research literature.

In marked contrast to the UK, Bennett and Ferns (2017) point out the employability of international students has been high on the research agenda in Australia. There the focus has been on the importance of work integrated learning (WIL) (Gribble et al., 2015; Tran \& Soejatminah, 2017). However, as Gribble et al. (2015) point out there is a gap between the promise of employability development, opportunities advertised, and lived experience for international students. In the UK context, there remains a gap in understanding how and to what extent international students engage with WIL. This article examines these gaps, drawing on a study that explored the perceptions of international students on developing their employability during a one-year Masters-level study abroad (Fakunle, 2019a). The focus is on how international students from a range of countries demonstrated their capacities for reflection and reflective thinking about the opportunities related to enhanced employability during their study abroad experience. It includes the extent to which 
their lived experience met these expectations of employability. The findings discussed in this paper raise the need for HEIs to support international student employability during their study abroad, specifically in relation to the opportunities (or lack of opportunities) to undertake work placement during their study abroad, and the implications for their future career trajectories.

\section{REFLECTIVE PRACTICE IN HIGHER EDUCATION}

Barton \& Ryan (2017) note it is difficult to define reflective thinking, as what is deemed to constitute a reflective act or practice partly depends on context. These authors highlight key aspects of reflection expected of learners in higher education, in relation to students' experience of assessment; feedback; and work integrated learning (WIL) (see Barton \& Ryan, 2017). They also noted that "despite its importance, reflection is not well implemented or undertaken, particularly in regard to explicit support for culturally diverse students and their supervisors" (p. 106). The importance accorded to reflection in discourse relating to higher education brings to the fore scholarly interest in how international students from non-western countries adjust to a different culture of teaching and learning. Much of the research in this area has focused on the lack of critical thinking of Chinese students in western universities from an academic perspective (Durkin, 2008; O'Sulivan \& Guo, 2010). However, the examination of Chinese literature shows that reflective thinking is present in Confucian culture (Tian \& Low, 2011). Empirical research also shows that Chinese students studying in the west demonstrate critical and reflective thinking (Fakunle et. al., 2016; Kingston \& Forland, 2008). Fakunle et al. (2016, p. 33) found that the Chinese students in their study struggled to understand the assessment requirement to show 'evidence of critical thinking'. The feedback from their first semester assignment served as a "trigger event" (Brookfield, 1987) for all six participants to reflect on their understanding. The findings revealed the differing perceptions of students in terms of how they perceived the development of critical thinking in their academic work.

In contrast, there is relatively little research in relation to international students' engagement in reflective practice in relation to the workplace components of their programs. Barton and Hartwig (2017) highlight the need for "systemic change within higher education institutions [HEIs] related to work placements and international students" as part of an integrated approach towards embedding employability in internationalization (p. 10). While it is crucial to understand practice related to work placements for international students (Barton \& Hartwig, 2017), it is also important to ascertain the extent to which international students perceive opportunities for WIL to be embedded in their programs. As will be discussed, Rodgers' (2002) four criteria of reflection capture international students' reflections on the extent to which they had access to EDOs within and outside the institution. Drawing on the work of Dewey (1933), Rodgers (2002) identified four criteria to illuminate the process as well as the purpose of reflection, which was regarded as a meaning-making process; as a rigorous way of thinking, as important in and for community; and as set of attitudes. As Rodgers (2002, p. 844) argued, the main purpose of reflection is to "derive meaning from experience" Similarly, we believe it is important to understand the reflections of international students in relation to how 
they make sense of a particular aspect of their experience, namely employability development opportunities (EDOs) during study abroad. The central question this article addresses is: How did the international students in the study reported below reflect on the wider implications of the absence of WIL opportunities?

\section{SETTING THE SCENE}

For the purpose of this article, international students are defined based on domiciliation, that is, they are resident in the UK for study purposes. The qualitative research upon which we draw below was conducted at one of the top five recruiting institutions for international students in the UK. The purposive selection of participants (Maxwell, 2013) made possible variability in the sample and inclusion of students from China and India (the biggest exporters of international students) and nine other countries (Canada, Columbia, Mexico, Nigeria, Singapore, South Africa, Taiwan, Turkey, and the US). Ethical approval for the study was granted by the university. To guide the focus of the research, a pilot study was conducted involving three students from two of the selected programmes. The participants $(n=19 ; 4$ males and 15 females) were recruited from four programs in four schools (Education; Business; Literatures; Languages and Cultures; and Social and Political Studies) in the university with the highest numbers of international students at the time the study was conducted. Two rounds of face-to-face semi-structured interviews $(\mathrm{n}=36)$ were conducted with the participants over the course of the one-year Master's program, at the end of the first and second semesters respectively. The specific programs are not identified (thereafter named as Programs 1 to 4) to ensure anonymity of the participants, and the names of all the students have been changed. The gender of the participants largely reflects the student cohort, for example, Program 1 did not have any male students enrolled when the study was conducted. For this article, we do not focus on demographics, such as, country of origin or gender. Rather, we focus on the shared characteristic of these international students as non-citizens in the host country because, as will be discussed, this singular factor had the greatest influence on how international students perceived the employability development opportunities afforded to them during study abroad. In other words, challenges around the affordances of EDOs in the host environment resonated with all participants, regardless of the variability of their country of origin.

All interviews were audio recorded and fully transcribed. The interviews were analysed thematically (Braun \& Clarke, 2006) using NVivo. Member checking was used to ensure the trustworthiness of the coded data into themes and categories. In this article, we focus on themes that emerged from the participants' narratives that capture and illustrate international students' perceptions of the work-integrated learning (WIL) opportunities afforded to them. These ranged from compulsory shortterm (i.e. up to one week) individual industrial placements with the option of an additional placement secured by the students themselves (Program 1); to longer placements with a research component and dissertation, with work-based mentors and academic supervisors (Program 2); and short-term group work experience placement in a company in Italy (Program 3). WIL was not offered as part of the course in Program 4. 


\section{INTERNATIONAL STUDENTS' PERCEPTIONS OF EMPLOYMENT DEVELOPMENT OPPORTUNITIES}

The findings presented below highlight variations in access to EDOs across four different Masters-level programs in a UK university. Invariably, the international students who participated in the study reflected on the extent to which they had access to EDOs within and outside the institution. Rodgers' (2002) criteria for reflection are of relevance here: first as a meaning-making process, as international students consider how their main motivation for studying abroad, that is, to enhance their employability, connects with their experience. Rodgers describes the second criterion as a rigorous way of thinking. This recalls Dewey's definition of education: "that reconstruction or reorganisation of experience which adds to the meaning of experience and which increases [one's] ability to direct the course of subsequent experience" (cited in Rodgers, 2002, p. 848). By making sense of the [taught and practical] components of their study, the participants needed to reassess their experience and what it meant to them, in order to assess the implications for further steps. As Rodgers noted, whilst meaning can be created in isolation, richer meanings can be derived from experience in community. This relates to Rodgers' third criterion namely as being important in and for community. The school/ program and the university constitute the immediate community for international students, as EDOs are linked to provision such as WIL embedded in courses. The wider community is relevant to facilitate WIL (such as work placements) conducted with organizations outside the university, or part-time work sourced by the students, as in Program 1. Rodgers (2002) deems a set of attitudes as the fourth criterion for reflection. Based on experience within the school community, this affective aspect of reflection could influence whether students express a positive or negative response to learning. Going back to Dewey, Rodgers (2002) points out that human attitudes fall into two categories: to see what we wish to see, rather than accept the evidence before us, or to believe the worst even if unsubstantiated. Below we draw on interviews with participants in order to illustrate their capacity for reflection under the following themes: seeking employability development opportunities within and outside the university; and (re)assessment of WIL.

\section{International Students' Meaning-Making Reflections on Employability Development Opportunities}

The meaning-making reflective process (Rodgers, 2002) demonstrated by the participants started before they embarked on their study abroad. The school website listed information regarding the different types of WIL embedded in the selected programs. Congruent with findings from a large-scale survey of international students (ICEF Monitor, 2019) the participants cited the institutional website as the main source of information about the program, including the EDOs they expected to engage in as a part of their study experience. For example, Adele (a student from Canada) explained what had attracted her to Program 2:

The work-based dissertation was something that drew me to this program because then you have a chance to network with different 
organizations when you're writing your dissertation and hopefully make contacts instead of just getting a sociology degree and being like, I have this now, somebody just hire me.

Adele's remarks are illustrative of the international students' accounts across different programs where WIL was embedded in the course of study. Adele did not respond to repeated invitations to attend the second interview held at the end of the second semester. Based on the discussions during the first interview, it was assumed that she had returned home to seek work opportunities which she had said were not available, as she had hoped. Her actions suggested an attempt at "reconstructing or reorganizing experience" of the reflection process (Rodgers, 2002, p. 855) as the international students made sense of their experience in planning their future steps.

As noted by Barton and Ryan (2017), processes of reflection can be triggered at different times depending on new encounters or issues. Similarly, in the context under study, the reflective processes were not linear for students across all four programs. For some of the international students in the study reported here, a fundamental factor accounting for a lack of participation in WIL was a lack of inclusion in the program. The absence of a practical WIL opportunity was another trigger for reflection. Of interest here is Rodgers' (2002) third criterion of reflection, that is, interaction with others in the community. Fang (a student from China on Program 4) discussed interest in work experience with a tutor. The tutor was supportive and provided guidance for her to secure a short-term volunteering position with an organization that specialized in learning technology for children. In line with her educational "quest" to attain her future goals, Fang demonstrated a resilient attitude that fits Rodgers' notion of reflection as "attitudes that value the personal and intellectual growth of oneself" (p. 845). The participants talked at length about their keen awareness of the value of WIL, including another student on Program 4, Indira (India) who pleaded for a "rounded education":

If given an opportunity I will like to tell them [the school] that please, have some kind of internship [WIL] in place for the students. Because Masters program is something that the internship could add value to. The benefit of that is that you get to work in an environment, and you can relate it to what you are studying. It gives you a more rounded effect.

Abby (USA) described the benefits of WIL offered in Program 1:

The strength of the Masters program is its applied practice component, which gives students the ability to work in real-world situations and learn from industry partners. After working with multiple festivals and film exhibition bodies in Scotland, I felt prepared enough to apply for a traineeship [internship] in film distribution in New York City. That I successfully got the job is a testament, in my opinion, to what I've been able to do this past year. So, I feel like my current study experience is not only relevant to my aspirations, but vital to them. 
The comments made by Abby encapsulate Rodgers' (2002) four criteria of reflection as: a meaning-making process (recognising the strength of the master's program, preenrolment and during study experience); as a rigorous way of thinking (analytic approach linking the master's to initial WIL and incremental work experience (internship) in both national and international contexts); in interaction with others (working with others); and attitudes and values (initiative and personal attributes to commit to pursuit and achievement of current and future goals). Abby's comments about satisfaction with the program resonated with comments from other students in Program 1, as well as two students in Program 3; Bond, (Singapore) and Yin (Taiwan) who were selected to participate in a week-long WIL opportunity.

Across all four programs, it was found that international students demonstrated reflection regarding the EDOs within and outside their schools. This meaning-making process occurred prior to their arrival and is evidenced in activities such as consulting the university website and selecting the program that best fitted their future career goals. Further on during their study, in the case where WIL was unavailable (Program 4), the students sought alternative work experience options, such as volunteering. They demonstrated commitment to their personal and intellectual growth which are attitudes captured in the reflective process (Rodgers, 2002). However, despite their keen interest, the lack of access to WIL was found to be a major barrier to enhancing EDOs. We now turn our attention to how international students (re)assessed the WIL opportunities during their study abroad.

\section{(RE)ASSESSMENT OF WORK INTEGRATED LEARNING OPPORTUNITIES}

Rodgers (2002) stated that "Dewey was acutely aware of the need to slow down the interval between thought and action" (p. 852). For international students, this suggests that they would benefit from a reassessment of their expectations and access to work experience (whether WIL or other types of work experience) during their study abroad. For the study participants, meaning-making processes were reassessed in the light of the opportunities and the barriers they faced with regards to their work prospects. This reassessment occurred mainly after the international students had checked the work opportunities, including part-time work, internships and volunteering positions advertised on the Careers Service website. Five out of the 19 participants engaged in part-time work unrelated to their master's program. Mariana (Colombia) and Jackie (USA) worked as waitresses. Sofia (Colombia) did some babysitting. Indira (India) and Bola (Nigeria) both worked for one day. In the case of Indira, she participated in a one-day university-run event. Bola did a social worker job and quit after one day. She described the job as more like a full-time job, and she reasoned that she could not cope with her studies and the demands of the job. Except for Indira and Bola, the participants who engaged in part-time jobs said this was primarily a way to augment their living costs while studying abroad. The rigour and the short length (one-year) of doing the master's was cited as a deterrent from seeking part-time work. As Lan (China) puts it, "the most realistic reason is because I pay my tuition fees for this program so I must study hard to learn knowledge well. To not make my money wasted." 
However, as the brief narrative below shows, Mariana added some important points related to doing part-time work:

My mum pays for my accommodation...The part-time work is to help my mum with the expenses because it is expensive to live here... I also think having a job helps you to kind of organise yourself. You manage your time wisely as you know that I have to work these days, so I have to have these days to study. So, it gives you discipline. And you know I like the fact that it allows you to meet people outside the university. You can switch your brain off and talk to normal people. It is a bit like you are always talking about your life and about theoretical stuff. Then at work you are like a normal person talking about the weather and I really like the people from my job. They are like really real people and I really like them. So it is like another social sphere. That is good to have as well. To escape from Uni I go to work.

Mariana's reflections above demonstrate an awareness of the benefits of part-time work as a way of developing employability related skills, such as, organisation skills and time management. She also raises the benefits of having time out from her studies to relate with people outside the university. These external opportunities for work experience could help international students to develop intercultural and interpersonal skills.

Abby (USA) did an internship in her home country. This demonstrated her keen interest in internships and resourcefulness to seek an EDO outside her host country. The participants, however, cited the lack of internships as a major issue. For example, Yin (Taiwan) shared details of her pursuit of a summer internship in another European Union (EU) country and how she was denied because the recruiter said she was not from an EU country. Based on their experience, international students cited two main reasons for their inability to undertake internships. Both reasons directly linked to their status as international students. The first reason was the student visa that provided a limited right to work. This meant that they could not undertake an internship during term time that exceeded the 20-hour permitted time to work. This highlighted inequities in internship opportunities during study period, as this was not an issue for their peers who were not international students. The second point related to a lack of interest by employers in recruiting international students, which Chao (China) and Fang (China) recounted as their experience when they attended the Careers Fair organised at the host institution. It seems ironic that Careers Fairs are organised for all students, however, it is unclear how international students are benefitting from such events if their status and affordances at the host community limits their access to EDOs during their study.

Whilst 11 students engaged in volunteering activities, Bola (Nigeria) reiterated the need for volunteering opportunities to be relevant to future career goals:

Whatever I have to volunteer for has to add knowledge and experience in my field of study. I am not a young scholar. I am an adult learner. Any moment for me now is valuable. I can't just waste it. I want focused experience and not scattered experience. I want something that will earn me an advantage. Like, whoa you got this experience in the UK! Not gaining experience 
cleaning the environment in the UK, because, if I want to work in high profile establishment it does not add up.

Narratives of the international students discussed so far provide snapshots of their reflection and reflective practice regarding their experiences and their meaning making through the challenges they faced. We will draw on the experience of one of the participants (Harshad) to illustrate the meaning-making processes of reflection over the course of the one-year master's study.

Harshad (India), a 22-year old student in Program 3 provided a cogent example of how international students re-assessed the work-placement opportunities, or the lack thereof, during their study experience. During the first interview, in the first few months after arrival in the UK, Harshad seemed very enthusiastic about the potential work opportunities afforded to him by studying abroad:

I have checked the website of the companies I want to apply to in the UK. I am in the first stage of the application process right now. I am applying for jobs. The biggest challenge is since I am an international student I require a visa to work over here and it is not very easy to get that. There are very few organisations who are willing to sponsor candidates and we need to express ourselves very well to try and get that visa. You have put in a lot of money and you want to have a good job. It's a hard situation. But since they are hiring the best I think it's alright. Not a big challenge. The chances are very bright. Very bright.

However, during the second interview, Harshad provided a clear illustration of how "one moves from an impressionistic sense to an articulated idea" (Rodgers, 2002, p. 854). By the end of the second semester, Harshad's optimism about work opportunity had dwindled considerably:

At first, my intention was to work in the UK for a couple of years then to go back to India. I heard that it's difficult. But getting a job is not easy in any part of the world so I said let's give it a try but when I came here, and I started applying it's almost impossible. The visa regulation makes it very difficult for us to get work in the UK. The organizations are not willing to sponsor non-EU people. A lot of organizations don't even consider the application. That makes me feel disappointed. It was always rejection at the very first stage in the online application. I get email in a couple of hours or the next day that my application cannot be processed to the next stage. EU people don't need visas, so they are progressing to the next stage. They have interviews. They are progressing nicely. The job market here is not in our [non-EU students] favour right now.

Based on his lived experience, Harshad revealed a deep understanding of systematic obstacles that undermined his efforts to secure work experience in the UK. In his case, these issues centred around the visa system in the UK. Some organizations may not have been UK Visa and Immigration (UKVI) licensed sponsors, which meant that 
they could not offer employment to non-EU nationals. UKVI-licensed sponsors need to pay administrative costs to employ non-EU citizens. The additional costs and resource implications of recruiting non-EU students are likely to deter employers. A caveat is warranted here. Brexit (the UK leaving the EU) means that visa policies for EU students are likely to change in the next few years. Furthermore, in 2020, changes to visa rules in the UK have seen the re-introduction of a two-year post-study work visa for international students. It remains to be seen how the changes in the visa policy will impact upon opportunities for international students to gain work experience.

Harshad's experience was not unique. Across the four programs, the participants cited several instances where individual attempts to seek part-time work and internship opportunities were thwarted. The main reason for the rejection of their application by employers was due to their status as international students. This points to one of the systemic flaws in the internationalization agenda, such as, issues around equality of access and the human rights of international students in the host country (Marginson, 2012). A lack of equality of access to work experience can be seen to deviate from what Dewey considers as the purpose of education for "intellectual, moral, and emotional growth of the individual and consequently, the evolution of democratic society" (Rodgers, 2002, p. 845). On the one hand, internationalization is an evolution of higher education society beyond national borders. As universities seek to internationalize, the student community has become more diverse. Yet it remains to be seen whether the internationalization agenda reflects the values of a democratic society in respect to equality of access, for example, to work opportunities. This question is important when considering the expectations of international students like Harshad who have expectations that studying abroad will equip them with the skills to live and work in a global world. This is how Harshad described the situation:

Today is a globalized world. If you want to work at a global level you need to understand different cultures, different perspectives. You need to understand how decision is made in different cultures. The organizations are working in global level and if you want work for an organization at the global level you need to understand how the process works.

Harshad was able to intellectualize the challenges related to a lack of opportunity to undertake a work experience. This was in marked contrast to his emotional response to questions during the first interview about work opportunities during study abroad. He created meaning out of his experience as part of a reflective process, along the lines proposed by Rodgers (2002). However, this meaning-making was not unproblematic. Having identified the problem, a great sense of relief at the stage of the reflective process (Rodgers, 2002) was lacking. Rather, Harshad evoked a sense of resignation. When asked about what support he expected from the university Harshad said:

I don't see the role of the university because the visa rules are formed by the government. And organizations have to stick to it. The university is obviously helping us to apply. They are willing to review our CVs. These things are more in the hands of government or organizations. 
Here Harshad showed a sense of disappointment and resignation as he could not see a path to work experience abroad. He reasoned that the support from the university was insufficient for him to access the work experience he wanted. He displayed a reflective attitude, in so far as he noted that different stakeholders, including the government, organizations, and the university, have different roles regarding the EDOs available to him.

It is important to recognize that like many of his peers Harshad's main criticisms were reserved for non-academic dimensions of university life, such as support services, rather than individual members of the academic staff. The tenor of these international students' observations about the deficiencies in their engagement with the careers service, for example, echoed the findings from the study by Arambewela and Maringe (2012). These authors stressed the need for universities to develop systems and support that are effective towards addressing the problems and challenges faced by international students. There has not been scope here to give an account of the type of dialogic encounters with faculty that international students on all four programs reported. For now, it will suffice to note that these lend further weight to the findings from other research to the effect that support from lecturers and tutors enhances the experience of international students (Lacina, 2002; Tran, 2008).

\section{CONCLUSION}

Our focus here has been on the reflections of international students on the WIL aspects of their study, as a means of furthering their legitimate career aspirations before embarking upon their studies. We drew attention to the best possible scenarios for international students who undertook programs with integrated WIL. We explored the challenges faced by some international students in attempting to secure a placement in situations where this was not a compulsory aspect of a program. Several demonstrated considerable resourcefulness and tenacity in seeking other opportunities to develop their employability. The international students who participated in the study reported here raised issues around a lack of equal access to part-time work opportunities in the host country, echoing the findings of other studies that examined issues around international students' employability. The progressive disillusionment of Harshad casts a long shadow. The brief snapshot of this case that we were able to present here underlines the fact that "reflection requires cognitive discipline [and] calls upon an individual's emotional discipline" (Rodgers, 2002, p. 863). Like many of his peers, Harshad remained "engaged in the experience as it [was] happening, in an undistracted way, so that data can be gathered through observation (whole-heartedness and directness)" (Rodgers, 2002, p. 863). His willingness to remain open-minded and to entertain many interpretations of his experience in order not to limit his understanding is apparent from the extracts of the interview transcript presented above. His case eloquently demonstrates that "one must accept that a shift in understanding of an experience may call for an entire shift in outlook" (Rodgers, 2002, p. 864).

The results of this study were evident in the international students' reflections on their experience through a meaning-making process and rigorous intellectual exercise. Their interpretation of their experience culminated in action, or in some cases in a realization of the limitations of individual agency. It is clear that the 
responsibility for enhancing employability among the international student population does not lie solely with the students themselves. The interview data indicate that support from staff was crucial towards facilitating relevant WIL projects. Yet it remains the case that not all students were successful in terms of achieving their desired outcomes. It is not possible here to do justice to the human and financial costs associated with this loss. The diverse experiences of international students suggest that there are gaps in provision that need to be examined and addressed. In agreement with recent studies in this area (Barton \& Ryan, 2017; Goodwin \& Mbah, 2019), there is a clear need for universities to implement support systems to address the problems and challenges international students face to access EDOs during their study abroad.

We recognise that the ameliorative intentions expressed above align with the second criterion for reflection identified by Rodgers (2002), namely a rigorous way of thinking that recalls a definition of education: "that reconstruction or reorganisation of experience which adds to the meaning of experience and which increases [one's] ability to direct the course of subsequent experience" (cited in Rodgers, 2002, p. 848). And yet, tinkering with the engine will not enable us to address adequately the consequences of the fundamental dichotomy to which we drew readers' attention at the beginning of this article. The dichotomy is between the internationalization agenda on the one hand, with its relentless focus of furthering the interests of the institutions whose business model is based on international recruitment, and the legitimate aspirations of the international students who embrace opportunities to study abroad as a means of enhancing their employment prospects in the long term. At the time of writing, it seems that the legacy of the COVID-19 pandemic may lead to a fundamental reassessment of a business model founded on international recruitment. The assumption that there is an international market for online learning that will partially compensate for international students' inability or reluctance to take up places on master's degree courses abroad seems open to question. If nothing else, it exposes a profound and deep-rooted systemic failure to recognise the legitimate career aspirations of international students who are well versed in the art of reflective practice.

\section{REFERENCES}

Arambewela, R., \& Maringe, F. (2012). Mind the gap: staff and postgraduate perceptions of student experience in higher education. Higher Education Review. 44(2), 63-84.

Archer, W. (2016). International taught postgraduate students: The UK's competitive advantage. London: HE International Unit.

Barton, G. M., \& Hartwig, K. (2017). The importance of positive intercultural exchanges for international students on work placements in higher education. In G. M. Barton \& M. Ryan (Eds.), Professional learning in the workplace for international students: Exploring theory and practice, (pp. 3-12). Springer.

Barton, G. M., \& Ryan, M. (2017). Reflection and reflective practice for international students and their supervisors in context. In G. M. Barton \& K. 
Hartwig. (Eds.), Professional learning in the workplace for international students: Exploring theory and practice, (pp. 93-110). Springer.

Bennett, D., \& Ferns, S. (2017). Functional and cognitive aspects of employability: implications for international students. In G. M. Barton \& K. A. Hartwig. (Eds.), professional learning in the workplace for international students: Exploring theory and practice, (pp. 203-224). Springer.

Braun, V., \& Clarke, V. (2006) Using thematic analysis in psychology. Qualitative Research in Psychology, 3(2), 77-101.

Brookfield, S. (1987). Developing critical thinkers: Challenging adults to explore alternative ways of thinking and acting. Open University Press.

Dewey, J. (1933). How we think. Prometheus Books.

Durkin, K. (2008). The adaptation of East Asian master's students to western norms of critical thinking and argumentation in the UK. Intercultural Education, 19, 15-27. https://doi.org/10.1080/14675980701852228

Fakunle, O. (2020) Developing a framework for international students' rationales for studying abroad, beyond economic factors. Policy Futures in Education https://doi.org/10.1177/1478210320965066.

Fakunle, O. (2019a). International student perceptions on studying abroad and developing employability during a UK Masters (Unpublished doctoral dissertation). The University of Edinburgh.

Fakunle, O. (2019b). 18 June. Empowering the student voice in internationalisation. World Education News +Reviews.

https://wenr.wes.org/2019/06/empowering-the-student-voice-in-internationalization

Fakunle, L., Allison, P. \& Fordyce, K. (2016). Chinese postgraduate students' perspectives on developing critical thinking on a UK Education Masters.

Journal of Curriculum and Teaching, 5(1), 27-38. http://dx.doi.org/10.5430/jctv5n $1 \mathrm{p} 27$

Gillies D. (2015). Human capital theory in education. In: Peters M. (Ed.) Encyclopaedia of Educational Philosophy and Theory. Springer, Singapore. https://doi.org/10.1007/978-981-287-532-7_254-1

Goodwin, K., \& Mbah, M. (2019). Enhancing the work placement experience of international students: towards a support framework, Journal of Further and Higher Education, 43(4), 521-532.

Gribble, C., Blackmore, J., \& Rahimi, M. (2015). Challenges to providing work integrated learning to international business students at Australian universities. Higher Education, Skills and Work-Based Learning, 5(4), 401416.

Kingston, E. \& Forland, H. (2008). Bridging the gap in expectations between international students and academic staff. Journal of Studies in International Education, 12, 204-221.

Huang, R., Turner, R. \& Chen, Q. (2014). Chinese international students' perspective and strategies in preparing for their future employability. Journal of Vocational Education and Training, 66(2), 175-193.

Hillage, J. \& Pollard, E. (1998). Employability: Developing a framework for policy analysis. Department for Education and Employment. 
ICEF Monitor (2019). Stealth applicants and the role of the institutional website. https://monitor.icef.com/2019/10/stealth-applicants-and-the-role-of-theinstitutional-website/.

Lacina, J. G. (2002). Preparing international students for a successful social experience in higher education. New Directions for Higher Education 117, (1), 21-27.

Lomer, S. (2018). UK policy discourses and international student mobility: The deterrence and subjectification of international students. Globalisation, Societies and Education, 16(3), 308-324. https://doi.org/10.1080/14767724.2017.1414584

Marginson, S. (2012). Including the other: Regulation of the human rights of mobile students in a nation-bound world. Higher Education 63, 497-512.

Maxwell, J. A. (2013). Qualitative research design: An interactive approach. Los Angeles: Sage.

Nilsson, P. A., \& Ripmeester, N. (2016). International student expectations: career opportunities and employability. Journal of International Students, 6(2), 614-631.

O’Sullivan, M. \& Guo, L. (2010). Critical thinking and Chinese international students: An East-West dialogue. Journal of Contemporary Issues in Education, 5, 53-73.

Page, A. G. \& Chahboun, S. (2019). Emerging empowerment of international students: How international student literature has shifted to include the students' voices. Higher Education, 78(5), 871-885. https://doi.org/10.1007/s10734-019-00375-7

Rodgers, C. (2002). Defining reflection: Another look at John Dewey and reflective thinking. Teachers College Record, 104(4), 842-866.

Tian, J. \& Low, G. D. (2011). Critical thinking and Chinese university students: A review of the evidence. Language, Culture and Curriculum, 24(1), 61-76. https://doi.org/10.1080/07908318.2010.546400

Tomlinson, M. (2008). 'The degree is not enough': Students' perceptions of the role of higher education credentials for graduate work and employability. British Journal of Sociology of Education, 29(1), 49-61. https://doi.org/10.1080/01425690701737457

Tran, L. T. (2008). Unpacking academic requirements: international students in management and education disciplines. Higher Education Research and Development, 27(3), 245-256. https://doi.org/10.1080/07294360802183804

Tran, L. T. \& Soejatminah, S. (2017). Integration of work experience and learning for international students: From harmony to inequality. Journal of Studies in International Education, 21(3), 261-277. doi: 10.1177/1028315316687012

Tymon, A. (2013). The student perspective on employability. Studies in Higher Education, 38(6), 841-856. https://doi.org/10.1080/03075079.2011.604408

Yorke, M. (2004). Employability in the undergraduate curriculum: some student perspectives. European Journal of Education, 39(4), 409-427. https://doi.org/10.1111/j.1465-3435.2004.00194.x 


\section{BIOGRAPHIES}

Omolabake Fakunle, $\mathrm{PhD}$, is a Teaching Fellow and Coordinator of the MSc Education General Pathway at the University of Edinburgh. She is a Fellow of Higher Education Academy (FHEA). She is Advisory Board Member, Journal of Comparative and International Higher Education, and Co-convenor, Scottish Educational Research Association ECR Network. Her award-winning research explores the intersections of internationalisation, student experience, employability and education policy. Omolabake has led and worked in multi-disciplinary teams on national and multi-national research projects on student experience in higher education. She shares her research widely in peer-reviewed journals, conferences, webinars, seminars and invited blog posts. Email: Omolabake.Fakunle@ed.ac.uk

Anne Pirrie, $\mathrm{PhD}$, is a Reader in Education at the University of the West of Scotland. Her recent work has been in the area of critical universities studies, culminating in the publication of a monograph entitled Virtue and the Quiet Art of Scholarship: Reclaiming the University (Routledge, 2019). She has also published on fostering reflective practice in HE; and critiques of the student satisfaction agenda that has gained traction in the UK higher education arena in recent years. This has entailed exploring the interrelationship between two discrete discursive fields. Email: Anne.Pirrie@uws.ac.uk 